\title{
Methylation and API2/MALT1 fusion in colorectal extranodal marginal zone lymphoma
}

\author{
Dong H Sinn ${ }^{1}$, Young-Ho Kim ${ }^{1}$, Eui $\mathrm{J} \mathrm{Lee}^{2}$, Young-Hyeh $\mathrm{Ko}^{2}$ and Kyoung-Mee Kim² \\ ${ }^{1}$ Department of Medicine, Samsung Medical Center, Sungkyunkwan University School of Medicine, Seoul, \\ Republic of Korea and ${ }^{2}$ Department of Pathology, Samsung Medical Center, Sungkyunkwan University \\ School of Medicine, Seoul, Republic of Korea
}

\begin{abstract}
Extranodal marginal zone B-cell lymphoma of mucosa-associated lymphoid tissue (MALT) is rarely found in the large intestine. Because of its rarity, the underlying epigenetic and genetic changes in the pathogenesis and prognostic factors have yet to be well established. For this purpose, methylation profiles and API2/MALT1 fusion in marginal zone B-cell lymphoma of MALT in the colorectum were studied and compared with treatment outcomes. For methylation analyses, 7 independent CpG islands (p15, p16, DAP kinase, hMLH1, MINT1, MINT2, and MINT31) were examined and RT-PCR for detection of API2/MALT1 fusion transcripts were performed in 15 colorectal marginal zone B-cell lymphoma of MALT in a single institution. Marginal zone B-cell lymphomas of MALT from both gastric and colorectal locations were also examined. In methylation analyses $(n=13), 8$ of 13 (62\%) cases were classified as CIMP (CpG island methylator phenotype)-positive. Methylation was more frequently observed in cases with advanced disease stages than with earlier stages; an average of two methylated loci for earlier stages (IE or IIE) versus four loci in advanced ones (IVE; $\boldsymbol{P}=0.02$ ). The estimated 5 -year progression-free survival was $42 \%$ for CIMP-positive and $100 \%$ for CIMP-negative cases $(P=0.03)$. API2/MALT1 fusion transcripts were found in two of nine cases (22\%). In two cases with concurrent gastric and colorectal involvement of marginal zone B-cell lymphoma of MALT, methylation patterns and API2/MALT1 fusion results were different by location. Our results suggest that methylation profiles define a clinically more aggressive subgroup and multiclonal origin for marginal zone B-cell lymphoma of MALT with multiorgan involvement.
\end{abstract}

Modern Pathology (2009) 22, 314-320; doi:10.1038/modpathol.2008.194; published online 5 December 2008

Keywords: methylation; API2/MALT1; lymphoma; B cell; intestine; large

Extranodal marginal zone B-cell lymphoma (EMZL) of mucosa-associated lymphoid tissue (MALT) is a distinct clinicopathologic entity with characteristic histologic features. ${ }^{1}$ EMZLs occur in a number of anatomic sites, but share overlapping morphologic and immunophenotypic features. Development of MALT lymphoma has been closely associated with chronic inflammation. This association is most evident between Helicobacter pylori gastritis and gastric EMZL and is supported by the evidence of tumor regression upon eradication of the microorganism alone. ${ }^{2}$ Focusing exclusively on gastric EMZLs, evidence suggests that these tumors develop along

Correspondence: Dr Young-Hyeh Ko, MD, PhD or Kyoung-Mee Kim, MD, PhD, Department of Pathology, Samsung Medical Center, Sungkyunkwan University School of Medicine, \#50, Ilwon-dong, Gangnam-Gu, Seoul 135-710, Republic of Korea.

E-mails: yhko0310@skku.edu or kkmkys@skku.edu

Received 11 July 2008; revised 3 November 2008; accepted 4 November 2008; published online 5 December 2008 two major molecular pathways that emerge from an oncogenic inflammatory milieu, one dependent on the presence of $t(11 ; 18)(q 21 ; q 21)$ representing the fusion of the API2 (apoptosis inhibitor-2) gene on chromosome 11 and the MALT1 (MALT lymphomaassociated translocation) gene on chromosome 18, and the other associated with a CpG island methylator phenotype (CIMP). ${ }^{3}$ The API2/MALT1 fusion gene, originally identified from a $\mathrm{t}(11 ; 18)(\mathrm{q} 21 ; \mathrm{q} 21)$ translocation, has been reported to be present in EMZLs. ${ }^{4}$ Lymphomas with this genetic aberration are predominantly found in $H$. pylori-independent cases of gastric EMZLs, do not respond to $H$. pylori eradication, show different frequencies in primary and secondary intestinal EMZLs, ${ }^{5}$ and display more aggressive behavior in the colorectum. ${ }^{6}$

Hypermethylation of $\mathrm{CpG}$ islands within promoter regions of genes is associated with transcriptional inactivation and represents an important mechanism of gene silencing in the pathogenesis of malignancy. ${ }^{7}$ Previous reports have shown that 
Table 1 Clinicopathologic findings of patients with MALT lymphomas in the colorectum

\begin{tabular}{|c|c|c|c|c|c|c|c|c|c|c|c|}
\hline $\begin{array}{l}\text { Case } \\
\text { no. }\end{array}$ & Age/sex & $L E L$ & $\begin{array}{c}\text { No. of } \\
\text { methylated } \\
\text { loci }\end{array}$ & $\begin{array}{l}\text { API2/ } \\
\text { MALT1 } \\
\text { fusion }\end{array}$ & $\begin{array}{l}\text { Involved } \\
\text { colon } \\
\text { segment }\end{array}$ & $\begin{array}{l}\text { Other } \\
\text { sites of } \\
\text { involvement }\end{array}$ & $\begin{array}{l}\text { Clinical } \\
\text { stage }\end{array}$ & $\begin{array}{l}\text { Treatment } \\
\text { response }\end{array}$ & Relapse & Survival & $\begin{array}{c}\text { Follow- } \\
\text { up } \\
\text { (months) }\end{array}$ \\
\hline 1 & $53 / \mathrm{M}$ & Present & 0 & - & Transverse & & $\mathrm{IE}$ & CR & - & Alive & 10 \\
\hline 2 & $51 / \mathrm{F}$ & Absent & 0 & Fail & Rectum & LNs & IIE & CR & - & Alive & 65 \\
\hline 3 & $58 / \mathrm{F}$ & Absent & 0 & Fail & Multiple & $\begin{array}{l}\text { Duodenum, } \\
\text { ileum, LNs }\end{array}$ & IVE & CR & - & Alive & 134 \\
\hline 4 & $44 / \mathrm{M}$ & Present & 2 & Fail & Rectum & & IE & CR & - & Alive & 20 \\
\hline 5 & $61 / \mathrm{F}$ & Absent & 2 & - & Rectum & & IE & CR & - & Alive & 132 \\
\hline 6 & $60 / \mathrm{F}$ & Present & 3 & - & Rectum & & IE & CR & - & Alive & 27 \\
\hline 7 & $32 / \mathrm{F}$ & Absent & 3 & + & Multiple & $\begin{array}{l}\text { Stomach, } \\
\text { tonsil, LNs }\end{array}$ & IVE & PD & + & Alive & 74 \\
\hline 8 & $44 / F$ & Absent & 4 & + & Sigmoid & Stomach & IVE & CR & - & Alive & 18 \\
\hline 9 & $55 / \mathrm{M}$ & Absent & 4 & - & Descending & $\begin{array}{l}\text { Omentum, } \\
\text { LNs }\end{array}$ & IVE & CR & + & Alive & 47 \\
\hline 10 & $84 / \mathrm{M}$ & Absent & 4 & Fail & Multiple & $\begin{array}{l}\text { Duodenum, } \\
\text { ileum, LNs }\end{array}$ & IVE & CR & + & DOD & 31 \\
\hline 11 & $64 / \mathrm{F}$ & Absent & 5 & - & Rectum & Lung, LNs & IVE & CR & - & Alive & 59 \\
\hline 12 & $78 / \mathrm{F}$ & Present & 5 & - & Multiple & LNs & IVE & CR & + & DOD & 93 \\
\hline 13 & $72 / \mathrm{F}$ & Absent & 7 & - & Ascending & Ileum, LNs & IVE & PR & + & Alive & 14 \\
\hline 14 & $82 / \mathrm{M}$ & Absent & Fail & Fail & Descending & LNs & IIE & PR & - & DU & 9 \\
\hline 15 & 73/M & Present & Fail & Fail & Rectum & Lung, LNs & IVE & CR & - & Alive & 18 \\
\hline
\end{tabular}

LEL, lymphoepithelial lesion; CR, complete response; PR, partial response; PD, progressive disease; LN, lymph node; DOD, died of disease; DU, died of unrelated cause; M, male; F, female; MALT, mucosa-associated lymphoid tissue.

inactivation of tumor suppressor genes by methylation is important in the development and malignant transformation of EMZLs. ${ }^{8-12}$ However, because of its rarity, methylation studies have not been described in colorectal EMZLs.

In this study, we analyzed methylation profiles and API2/MALT1 fusion gene transcripts in patients with EMZL in the colorectum. In addition, in cases with synchronous multifocal involvement in the stomach and large intestine, EMZLs from both gastric and colorectal locations were analyzed simultaneously.

\section{Materials and methods}

\section{Materials}

Between January 1996 and August 2007, twenty cases of EMZL of the colon and rectum were identified from databases in the Department of Pathology of Samsung Medical Center, Seoul, Korea. The paraffin-embedded tissue was sectioned, H\&E stained, and reviewed by two pathologists (YH Ko and $\mathrm{KM} \mathrm{Kim}$ ). Additional immunohistochemical stain for CD3, CD5, CD10, CD 20, CD23, cyclin D1, and Ki-67 (DAKO, Copenhagen, Denmark) was also examined. Of 20 cases, 5 were excluded because of very low tumor cell populations and polyclonality in the immunoglobin heavy chain rearrangement $(n=3)$, positive staining for cyclin D1 $(n=1)$, and no paraffin block $(n=1)$.

Clinical data were collected from the patients' medical records including demographic information, initial presenting symptoms, the presence of $\mathrm{B}$ symptoms, disease stages, types of initial treatment, dates of diagnosis, and last follow-up. There was no patient with an identifiable autoimmune disease assessed by clinical symptoms and laboratory findings. Two patients were positive for HBV antigen and all of the cases were negative for HCV infection.

Staging procedures included chest X-ray, computerized tomography, endoscopic evaluations with multiple biopsies, Waldeyer's ring examination, and bilateral bone marrow aspiration with biopsies. All patients were clinically staged according to Musshoff's modification of the Ann Arbor system. ${ }^{13}$ Patients with multiple lesions in the gastrointestinal tract were incorporated into stage IV according to the suggestion of a previous study. ${ }^{14}$ Cases that were thought to be secondary involvement or primary organ undetermined were excluded from the present series.

The study was approved by the institutional review board and carried out in accordance with the ethical guidelines of the research review committees of the institutions in Amsterdam and Utrecht.

\section{Methylation Analyses Using Methylation-Specific PCR}

To assess methylation status, methylation-specific PCR (MSP) was performed using the primer sets previously reported..$^{1,12,15,16}$ The methylation status of seven independent CpG islands, including $p 15$, p16 (tumor suppressor gene), DAP kinase (apoptosis-related), hMLH1 (mismatch repair gene), MINT1, MINT2, and MINT31 (methylated clones) were examined. Methylation of these genes was detected in some cases of lymphomas and cases with promoter methylation at three or more out of seven 
316
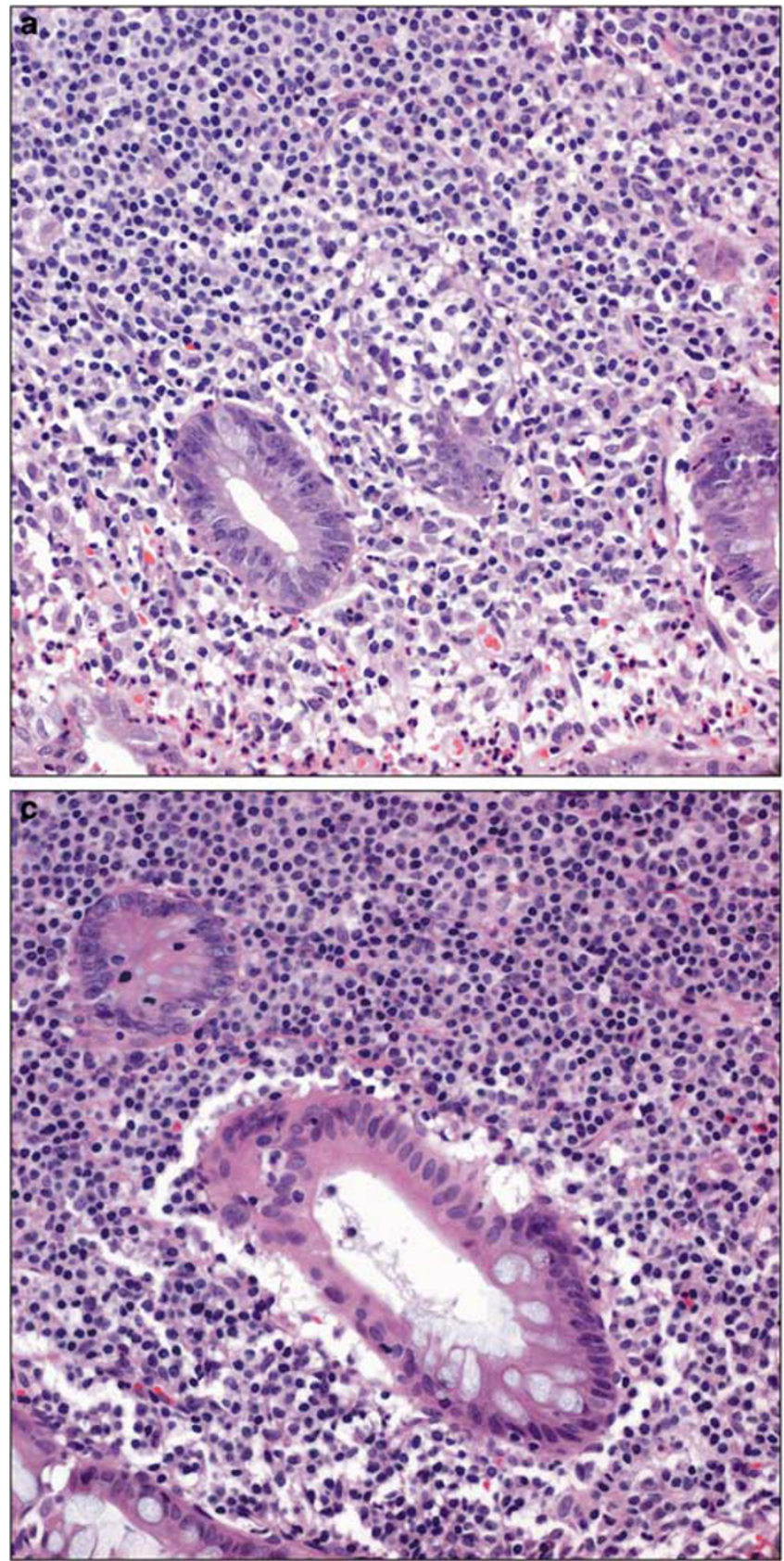
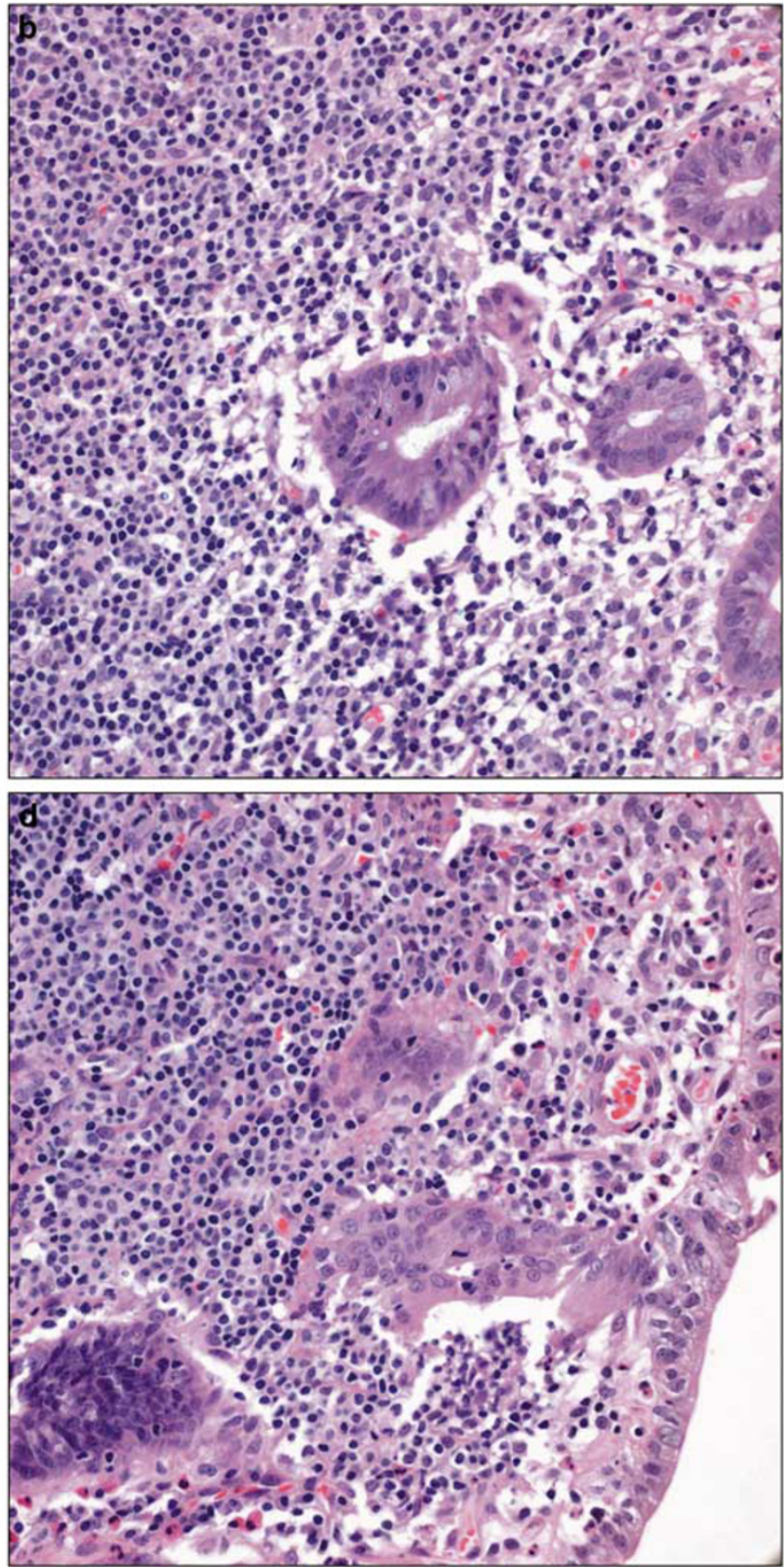

Figure 1 Lymphoepithelial lesion found in extranodal marginal zone B-cell lymphoma of MALT in the colorectum from (a) case 1 (b) case 4 (c) case 12, and (d) case 15.

loci $(>42 \%)$ were defined as CIMP-positive phenotype as described previously. ${ }^{17}$

\section{RT-PCR for API2/MALT1 Fusion Transcripts}

The API2/MALT1 fusion transcripts were detected using archival paraffin sections according to Inagaki et al. ${ }^{18}$ Briefly, RNA was extracted using a Pinpoint ${ }^{\mathrm{TM}}$ slide RNA isolation system II (ZYMO Research, CA, USA) with serial hematoxylin and eosin sections. In the first round of multiplex RT-PCR, three different primer pairs (PA1-PM2, PA3-PM4, and PA5-PM6 for the API2/MALT1 fusion transcripts) were added to the reaction mixture. The first-round RT-PCR product was diluted with water and was subjected to three parallel second-round multiplex nested PCRs. To detect fusion genes with an API2 breakpoint at bp 1203, primers PA2, PM1, PM3, and PM5 were included in the second-round multiplex PCR (second PCR-A). To detect fusion genes possessing API2 breakpoints at bp 1446 and bp 1701 or bp 1743, the second-round PCR used two primer sets, ie, PA4, PM1, PM3, and PM5 (second PCR-B) for bp 1446 and PA6, PM1, PM3, and PM5 (second PCR-C) for bp 1701 or 1743 , as previously described. ${ }^{19}$ To avoid 

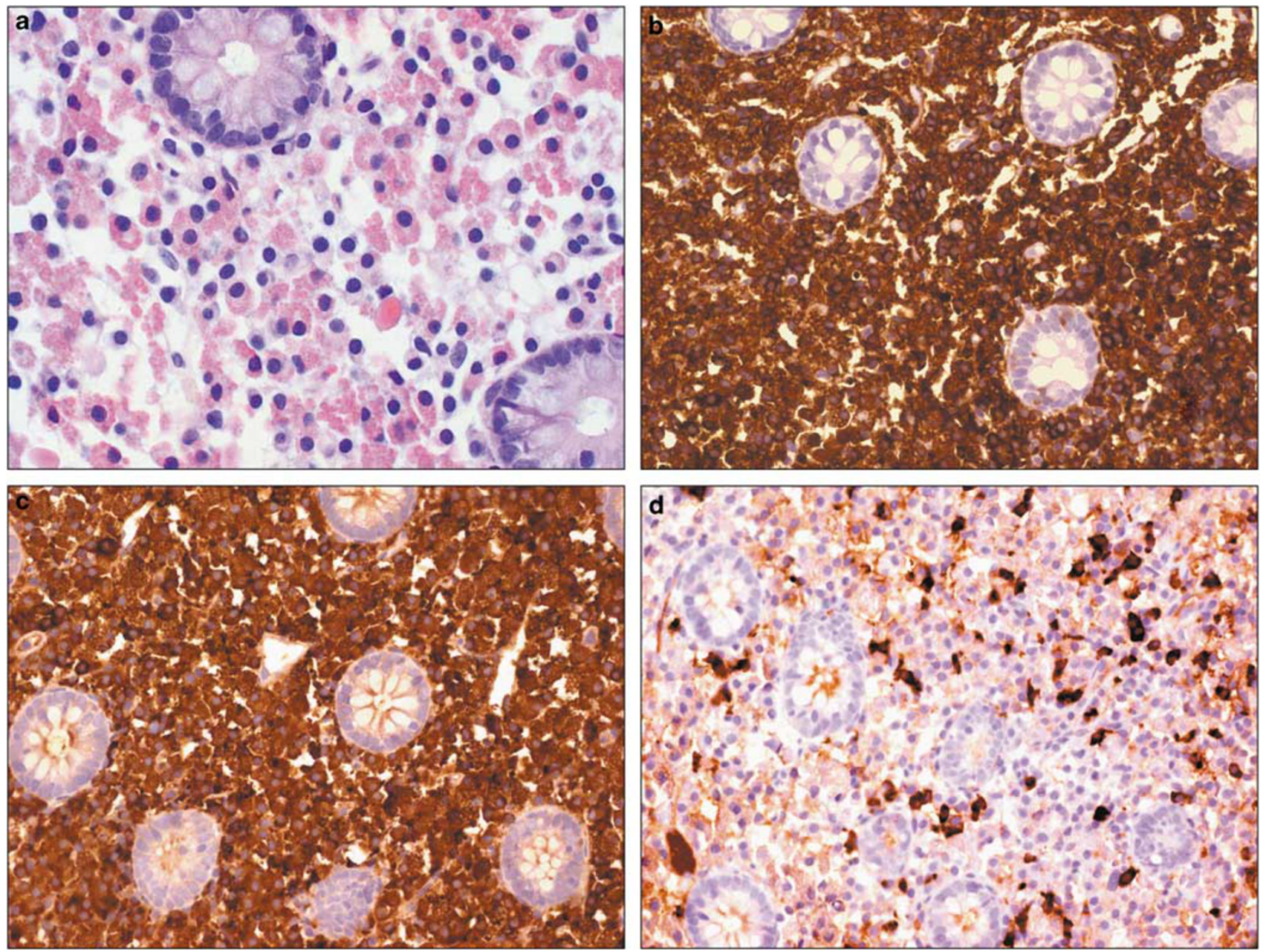

Figure 2 Extranodal marginal zone B-cell lymphoma of MALT from case 13. (a) Histologic findings; (b) tumor cells showing strong positive for CD79a; (c) immunohistochemical stain for kappa light chain is strongly diffuse positive; and (d) immunohistochemical stain for $\lambda$-immunoglobulin light chain is negative.

false-negative results, $\beta$-actin mRNA was amplified as an internal positive control.

\section{Statistical Analysis}

Progression-free survival was defined as the duration from the day of diagnosis or chemotherapy to the detection of new lesions or the progression of residual lesions. Overall survival was defined as the duration from the day of diagnosis to death. Progression-free survival and overall survival were estimated using Kaplan-Meier methods. Survival rates were compared for statistical differences by log-rank analysis and $P$-values of less than 0.05 were considered statistically significant.

\section{Results}

\section{Clinicopathologic Findings and Treatment Outcome}

The initial presenting symptoms of patients with colorectal EMZLs included abdominal pain $(n=5)$, gastrointestinal bleeding $(n=3)$, altered bowel habits $(n=3)$, and mucoid stool $(n=2)$. B symptoms were present in two patients with multiorgan involvement. In total, 7 of 15 patients (47\%) had involvement of at least two MALT organs as documented by staging, but these extracolorectal lesions were not a predominant form. Two patients showed gastric involvement of EMZL. $H$. pylori infection was identified in none of the thirteen patients in whom endoscopic biopsy of the gastric mucosa was performed. Clinical stages and involved colon segments are described in Table 1.

Of the 15 cases of EMZLs, lymphoepithelial lesion was identified in 5 cases (33.3\%; Figure 1). Infiltrating tumor cells were located in the mucosa and submucosa and were positive for CD20. In two cases (cases no. 13 and 15), massive plasmacytic differentiation with many Russel bodies was observed, in which tumor stages were IVE with multiorgan involvement (Figure 2). For treatment, 3 patients with stage IE had local treatment alone (radiation and/or resection) and 12 patients received systemic chemotherapy. Of the 15 treated patients, 12 achieved 


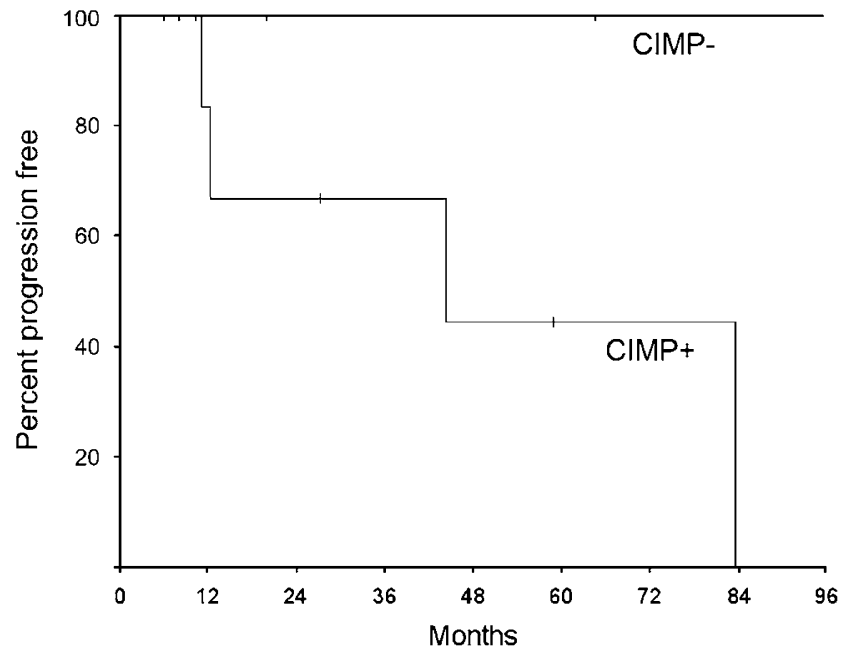

Figure 3 Progression-free survival according to methylation profiles. Patients with CIMP-positive showed shorter progression-free survival than CIMP-negative cases.

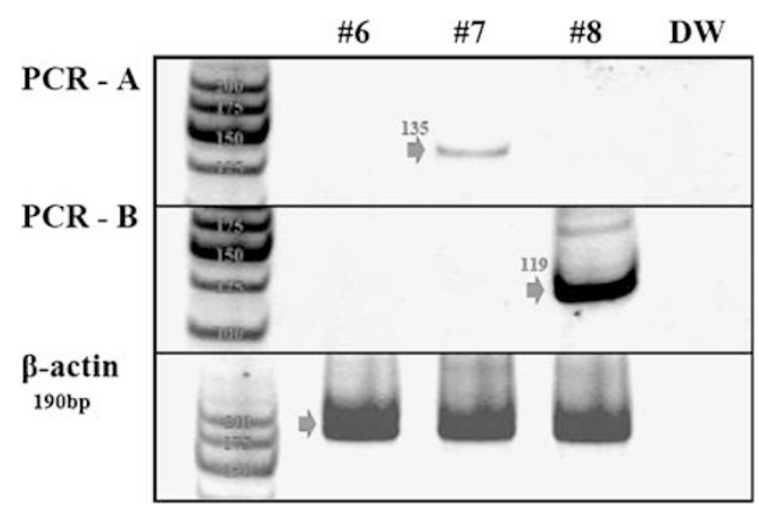

Figure 4 RT-PCR amplification for the API2/MALT1 fusion gene and for the $\beta$-actin gene isolated from extranodal marginal zone B-cell lymphoma of MALT. A $135 \mathrm{bp}$-sized product was identified in the second PCR-A and $119 \mathrm{bp}$-sized band in the second PCR-B.

a complete response after initial treatment and 3 of them had relapses during a follow-up period of 11-192 months after treatment. The estimated 5-year overall survival was $87 \%$ during a median of 31.0 months of follow-up. The estimated 5-year progression-free survival was $65 \%$ with a median progression-free survival of 83.6 months.

\section{Methylation Profile and Clinical Outcome}

The results of MSP are summarized in Table 1. Methylation studies were successful in 13 cases. Methylation was more frequently observed in cases with advanced disease stages than with earlier stages; an average of 2 loci methylated for earlier stages (IE or IIE) versus 4 loci for advanced ones (IVE; $P=0.02$ ). According to CIMP criteria, eight cases (62\%) were classified as CIMP-positive and all but one CIMP-positive tumor were stage IVE. Five

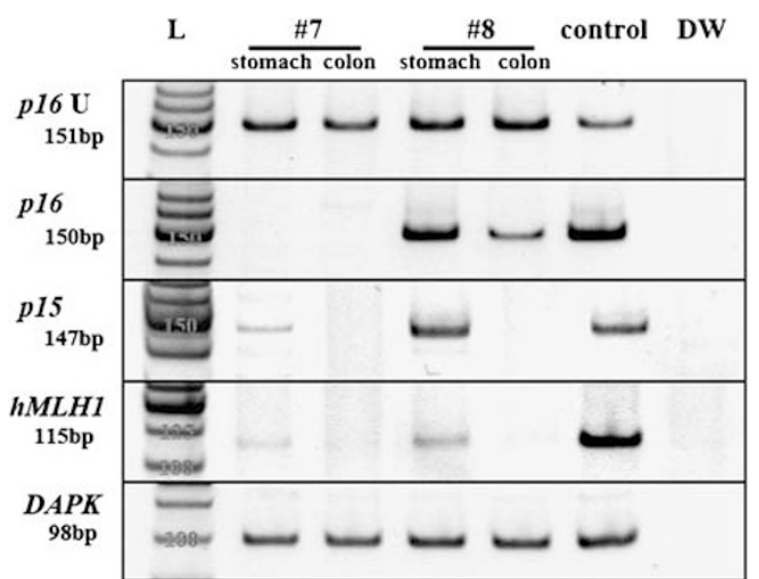

Figure 5 Methylation pattern in two patients with synchronous gastric and colorectal involvement of extranodal marginal zone B-cell lymphoma of MALT. Distinct methylation patterns were observed between gastric and colorectal tissues from case nos. 7 and 8.

CIMP-positive patients showed disease progression, whereas none of five CIMP-negative patients demonstrated disease progression. Disease-related death occurred in two CIMP-positive patients whereas all CIMP-negative patients were alive during follow-up. The estimated 5-year progression-free survival was statistically different according to CIMP status; $42 \%$ for CIMP-positive and $100 \%$ for CIMP-negative cases, respectively $(P=0.03$; Figure 3$)$. Tumor stage $(100,50$, and $53 \%$ for stages IE, IIE, and IVE, respectively, $P=0.3$ ) or age (53 and $71 \%$ for ages $<60$ and $\geq 60$, respectively, $P=0.8$ ) was not statistically significant in relation to progression-free survival. Because of a limited number of cases and relatively short median survival, statistical analyses for overall survival and multivariate analyses for progression-free survival failed.

\section{RT-PCR for API2/MALT1 Results}

In our series, API2/MALT1 fusion study was successful in nine patients and API2/MALT1 fusion was positive in two colorectal EMZL cases (22\%), and the fusion types were A1203-M1123 (135 bp band in the second PCR-A) and A1446-M814 (119 bp band in the second PCR-B; Figure 4). The subsequent sequencing analyses confirmed these results. These fusion transcripts were found in patients with stage IVE disease (cases no. 7 and 8), in which concurrent gastric and colorectal involvement of EMZLs were observed. In two cases with synchronous involvement of both stomach and colon, methylation analyses and API2/MALT1 RT-PCR studies were performed at the same time. Strikingly, methylation patterns and API2/MALT1 results differed between the two sites (Figure 5). In these two cases, colonic EMZLs were positive for the API2/MALT1 fusion, whereas gastric EMZLs were negative. At follow-up, 
disease progression was found in one patient, and the others achieved a complete response with chemotherapy (Table 1).

\section{Discussion}

EMZLs account for approximately $7-8 \%$ of all nonHodgkin lymphomas, and the stomach is the most common and best-studied site of involvement. ${ }^{20}$ The overall incidence of EMZL in the intestine is quite low and accounts for only about $2.7 \%$ of all cases of gastrointestinal non-Hodgkin lymphomas. ${ }^{21}$ Primary colorectal lymphoma accounts for only about $0.2 \%$ of large intestinal malignancies. ${ }^{22}$ Moreover, colorectal EMZLs differ from gastric variants not only in terms of the etiologic infectious organism but also in terms of its clinical presentation and treatment. ${ }^{23}$

The exact percentage of patients affected by clinically apparent multiorgan disease upon diagnosis is not known in colorectal EMZLs. Unlike previous observations on gastric EMZLs, ${ }^{24,25}$ lymph node involvement was frequently found in our cases and $60 \%$ of patients with colorectal EMZLs were stage IV disease. These findings strongly suggest that patients presenting with apparent colorectal primary EMZL need particularly thorough staging evaluation.

The initial site of multiorgan EMZL is a problematic issue. Previous reports indicate that, in most EMZL patients with multiorgan involvement, the multiple lesions consisted of an identical clone. ${ }^{24}$ However, some suggested that a considerable number of patients with multifocal EMZL had different lymphoma cell clones develop simultaneously in different lesions. ${ }^{26}$ In our study, we observed distinct methylation profiles and genetic aberrations in two cases with concomitant gastric and colorectal involvement. Thus, it is likely that in some patients with multiorgan involvement of EMZL, different tumor clones develop simultaneously at different sites.

In this first study of DNA methylation in colorectal EMZLs, hypermethylation at multiple loci of $\mathrm{CpG}$ islands were associated with advanced clinical stages. Hypermethylation at multiple promoter regions of genes was also associated with shorter progression-free survival. We found that five-year progression-free survival was different according to CIMP status. Although we were able to study only a limited number of cases, we found that CIMP status was a better predictor than clinical tumor stages in determining the prognosis of patients. The hypermethylated subtype (CIMP-positive phenotype) in tumors is a novel marker for tumor progression. ${ }^{27}$ Methylation of multiple genes is often associated with shortened survival after standard therapy. ${ }^{28}$ Based on these observations, methylation profiles in colorectal EMZLs will provide useful information about its clinical behavior and CIMP-positive tumors should be managed as a more aggressive subgroup.
The frequency of API2/MALT1 fusion varies in EMZLs of various anatomical sites from 0 to $50 \%$ and occurs less frequently in the colon $(10-20 \%) .^{29}$ There are four known breakpoints in each API2 and MALT1 gene, and eight variants of API2/MALT1 fusion transcripts have been reported. In our study in a single institution, fusion of API2/MALT1 was found in $22 \%$, which is similar to previous studies. ${ }^{6,29}$ In the stomach, fusion-positive EMZL is characterized as chronic inflammation independent, having advanced clinical stage and frequent nodal involvement. In our colorectal cases, all fusionpositive cases were clinically advanced and this result is consistent with a previous report. ${ }^{6}$ API2/ MALT1 fusion is often detected as the sole chromosomal alteration and is a gene abnormality specific to EMZL. ${ }^{29}$ In our two fusion-positive cases, they showed rare methylation in the colorectal location harboring fusion whereas their gastric counterparts without fusion showed frequent methylation. Our results suggest that not only genetic but also epigenetic changes are rare in fusion-positive EMZLs.

In conclusion, different epigenetic and genetic findings observed in our synchronous gastric and colorectal locations support a multiclonal origin for EMZLs with multiorgan involvement. The CIMPpositive phenotype in colorectal EMZL was associated with an advanced disease stage and poor clinical outcome, which warrants more aggressive treatment. This phenotype may predict adverse clinical behavior and CIMP-positive tumors should be treated as a more aggressive subgroup.

\section{Acknowledgement}

This study was supported by a grant from Korean Research Foundation to Dr Kim KM (2005-E00028).

\section{References}

1 Isaacson $\mathrm{P}$, Wright $\mathrm{DH}$. Malignant lymphoma of mucosa-associated lymphoid tissue. A distinctive type of B-cell lymphoma. Cancer 1983;52:1410-1416.

2 Isaacson PG, Spencer J. The biology of low grade MALT lymphoma. J Clin Pathol 1995;48:395-397.

3 Farinha P, Gascoyne RD. Molecular pathogenesis of mucosa-associated lymphoid tissue lymphoma. J Clin Oncol 2005;23:6370-6378.

4 Remstein ED, James CD, Kurtin PJ. Incidence and subtype specificity of API2-MALT1 fusion translocations in extranodal, nodal, and splenic marginal zone lymphomas. Am J Pathol 2000;156:1183-1188.

5 Streubel B, Seitz G, Stolte M, et al. MALT lymphoma associated genetic aberrations occur at different frequencies in primary and secondary intestinal MALT lymphomas. Gut 2006;55:1581-1585.

6 Sakugawa ST, Yoshino T, Nakamura S, et al. API2MALT1 fusion gene in colorectal lymphoma. Mod Pathol 2003;16:1232-1241. 
7 Jones PA, Laird PW. Cancer epigenetics comes of age. Nat Genet 1999;21:163-167.

8 Martinez-Delgado B, Fernandez-Piqueras J, Garcia MJ, et al. Hypermethylation of a $5^{\prime} \mathrm{CpG}$ island of p16 is a frequent event in non-Hodgkin's lymphoma. Leukemia 1997;11:425-428.

9 Herman JG, Civin CI, Issa JP, et al. Distinct patterns of inactivation of p15INK4B and p16INK4A characterize the major types of hematological malignancies. Cancer Res 1997;57:837-841.

10 Villuendas R, Sanchez-Beato M, Martinez JC, et al. Loss of p16/INK4A protein expression in non-Hodgkin's lymphomas is a frequent finding associated with tumor progression. Am J Pathol 1998;153:887-897.

11 Martinez-Delgado B, Ri, Garcia MJ, et al. Hypermethylation of P16ink4a and P15ink4b genes as a marker of disease in the follow-up of non-Hodgkin's lymphomas. Br J Haematol 2000;109:97-103.

12 Min KO, Seo EJ, Kwon HJ, et al. Methylation of p16(INK4A) and p57(KIP2) are involved in the development and progression of gastric MALT lymphomas. Mod Pathol 2006;19:141-148.

13 Carbone PP, Kaplan HS, Musshoff K, et al. Report of the Committee on Hodgkin's disease staging classification. Cancer Res 1971;31:1860-1861.

14 Ruskone-Fourmestraux A, Dragosics B, Morgner A, et al. Paris staging system for primary gastrointestinal lymphomas. Gut 2003;52:912-913.

15 Herman JG, Graff JR, Myohanen S, et al. Methylationspecific PCR: a novel PCR assay for methylation status of CpG islands. Proc Natl Acad Sci USA 1996;93:9821-9826.

16 Kang GH, Shim YH, Jung HY, et al. CpG island methylation in premalignant stages of gastric carcinoma. Cancer Res 2001;61:2847-2851.

17 Toyota M, Ahuja N, Suzuki H, et al. Aberrant methylation in gastric cancer associated with the $\mathrm{CpG}$ island methylator phenotype. Cancer Res 1999;59:5438-5442.

18 Inagaki H, Okabe M, Seto M, et al. API2-MALT1 fusion transcripts involved in mucosa-associated lymphoid tissue lymphoma: multiplex RT-PCR detection using formalin-fixed paraffin-embedded specimens. Am J Pathol 2001;158:699-706.
19 Kim WS, Honma K, Karnan S, et al. Genome-wide array-based comparative genomic hybridization of ocular marginal zone B cell lymphoma: comparison with pulmonary and nodal marginal zone B cell lymphoma. Genes Chromosomes Cancer 2007;46:776-783.

20 Zucca E, Bertoni F, Roggero E, et al. The gastric marginal zone B-cell lymphoma of MALT type. Blood 2000;96:410-419.

21 Koch P, del Valle F, Berdel WE, et al. Primary gastrointestinal non-Hodgkin's lymphoma: I. Anatomic and histologic distribution, clinical features, and survival data of 371 patients registered in the German Multicenter Study GIT NHL 01/92. J Clin Oncol 2001;19:3861-3873.

22 Dionigi G, Annoni M, Rovera F, et al. Primary colorectal lymphomas: review of the literature. Surg Oncol 2007;16(Suppl 1):S169-S171.

23 Zinzani PL, Magagnoli M, Pagliani G, et al. Primary intestinal lymphoma: clinical and therapeutic features of 32 patients. Haematologica 1997;82: 305-308.

24 Yoshino $\mathrm{T}$, Ichimura $\mathrm{K}$, Mannami $\mathrm{T}$, et al. Multiple organ mucosa-associated lymphoid tissue lymphomas often involve the intestine. Cancer 2001;91:346-353.

25 Raderer M, Vorbeck F, Formanek M, et al. Importance of extensive staging in patients with mucosa-associated lymphoid tissue (MALT)-type lymphoma. Br J Cancer 2000;83:454-457.

26 Iwano M, Okazaki K, Uchida K, et al. Characteristics of gastric B-cell lymphoma of mucosa-associated lymphoid tissue type involving multiple organs. J Gastroenterol 2004;39:739-746.

27 Kaneko Y, Sakurai S, Hironaka M, et al. Distinct methylated profiles in Helicobacter pylori dependent and independent gastric MALT lymphomas. Gut 2003;52:641-646.

28 Issa JP. Methylation and prognosis: of molecular clocks and hypermethylator phenotypes. Clin Cancer Res 2003;9:2879-2881.

29 Inagaki H. Mucosa-associated lymphoid tissue lymphoma: molecular pathogenesis and clinicopathological significance. Pathol Int 2007;57:474-484. 